\title{
Design and Analysis of Vacuum Pumping Systems for Spallation Neutron Source Drift-Tube Linac and Coupled-Cavity Linac*
}

\author{
$\underline{\text { S. Shen }}^{+}$, L. Tung, K. Kishiyama, W. Nederbragt, \\ Lawrence Livermore National Laboratory, Livermore, CA \\ John Bernardin, G. Bustos, R. Gillis, R. Meyer Sr. \\ Los Alamos National Laboratory, Los Alamos, NM
}

\begin{abstract}
The mechanical design of the vacuum pumping systems for SNS (Spallation Neutron Source) DTL (Drift Tube Linac) and CCL (Coupled Cavity Linac) linac systems is summarized. Both vacuum systems were modeled to select the optimal pump configuration. The pressure history in up to 182 sub-volumes was analyzed in detail. Included in the model are time-dependent outgassing rates and pressure-dependent pump speeds for a variety of gas species. With this information, we solved for the pressure history during roughing and with turbo and ion pumps. The number and size of each pump were optimized to achieve the desired pressure with minimal costs. In the optimized design, directly mounted ion pumps were provided for six DTL tanks. For four CCL modules (each in length of 12-15 m), ion pumps with manifolds were selected. With all metallic surface outgassing, seal leakage and expected gas loads from all diagnostic devices taken into account, the designed systems can provide operating drift-tube pressure below $1.8 \times 10^{-7}$ Torr and CCL beamline pressures below $9.2 \times 10^{-8}$ Torr even under abnormal conditions. Details of the design and the modeling results are presented.
\end{abstract}

\section{INTRODUCTION}

The Spallation Neutron Source (SNS) is an acceleratorbased neutron research facility being constructed for scientific and industrial R\&D. The SNS will produce neutrons by bombarding a heavy metal target with a highenergy beam of protons, generated and accelerated with a linear particle accelerator, or linac. To effectively accelerate the protons, the linac requires an evacuated environment. This vacuum serves two purposes. First, the gas pressure in the accelerating structure must be minimized to a level $\left(<10^{-6}\right.$ Torr $)$ acceptable for the Radio Frequency (RF) energy to propagate within the copper structure. Second, a low gas density is required along the beam line to minimize collisions of the protons with gas molecules. The SNS Linac is comprised of three main structures including the Drift Tube Linac (DTL), the Coupled Cavity Linac (CCL), and the Superconducting Linac (SCL). The DTL is the first structure following the ion injector and Radio Frequency Quadrupole (RFQ). The 402.5 MHz Alverez DTL is used to accelerate the $\mathrm{H}^{-}$ beam from $2.5 \mathrm{MeV}$ to $86.8 \mathrm{MeV}$, and the CCL continues

\footnotetext{
* Work supported by the US Department of Energy under Contract W-7405-Eng-48.

${ }^{\dagger}$ Email: shen2@1lnl.gov
}

to increase the energy to $187 \mathrm{MeV}$. The system configuration is illustrated in Fig. 1.

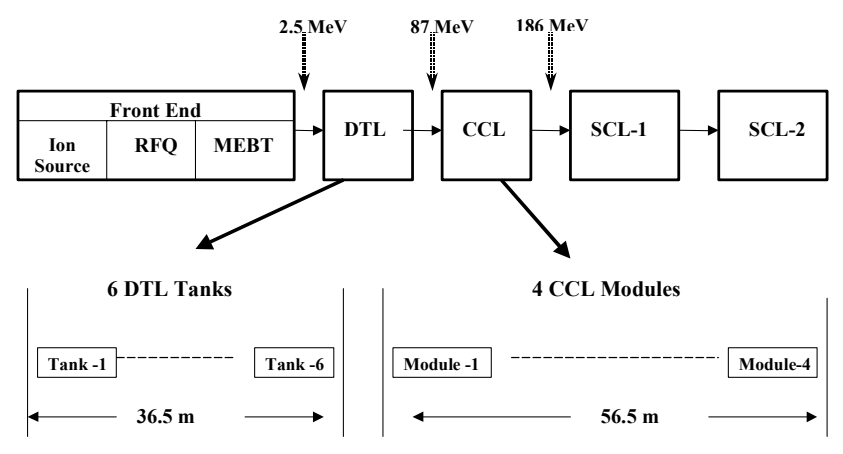

Figure 1: System Layout for the SNS Linac.

\section{DESIGN CONCEPTS}

\subsection{System Requirements}

The primary requirement for the DTL and CCL vacuum systems is to provide sufficient pumping to overcome the surface outgassing of vacuum facing components and maintain a beam tube pressure that is below the values required for a $2-\mathrm{mA} \mathrm{H}^{-}$beam operation. The maximum allowable pressure in the DTL and CCL, is a function of beam energy [1]. Other general requirements include providing mechanical interfacing, ensuring operation reliability with practical maintainability plan, and minimizing the costs. Note that all the pressure values correnpond to the mixed-gas pressures averaged over a beam tube length of 5 meters.

\subsection{Design Approach}

For both DTL and CCL systems, we have set up a design goal for a pressure that is half of the base pressure limits, in order to have an operating margin of two. Additionally, maintaining a base pressure in the event that one pump failed is also included in the design goals.

Turbo and scroll pumps, mounted on a portable cart, have been chosen for roughing down the vacuum environment and providing initial vacuum conditioning. These pumps are used to lower the pressure below $10^{-5}$ Torr, after which ion pumps, used for steady-state vacuum pumping, can be turned on. Ion pumps were chosen for steady-state operation because of their reliability and lack 


\section{SNS/DTL Tank 2 layout for volumes and conductances}

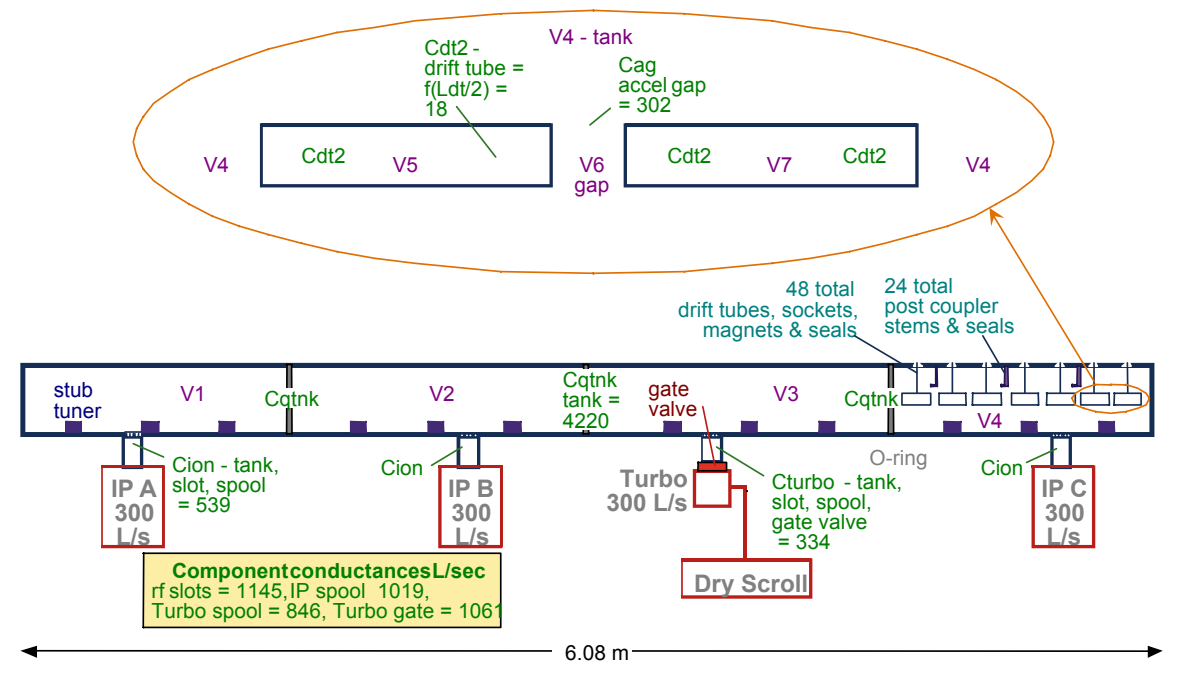

Fig. 2: Layout of the analytical model of the DTL Tank 2

of the need for a backing pump. The surface- outgassing rate of the annealed OFE copper is assumed to reach $1.0 \times 10^{-10}$ Torr- $\mathrm{L} / \mathrm{s} / \mathrm{cm}^{2}$ after 100 hours of vacuum and RF conditioning. To achieve this outgassing rate, RF power is turned on to provide surface heating and molecular excitation to drive out trapped and adsorbed gases. During vacuum conditioning, the turbo pumps and ion pumps can be used to maintain $1.0 \times 10^{-6}$ Torr until conditioning is complete and the outgassing rate drops to the postconditioning value of $1.0 \times 10^{-10}$ Torr- $\mathrm{L} / \mathrm{s} / \mathrm{cm}^{2}$. Table 1 and Table 2 summarize many of the vacuum system design requirements for the DTL and CCL respectively.

Table 1: SNS/DTL Vacuum System Requirements

\begin{tabular}{|c|c|c|}
\hline \multicolumn{2}{|l|}{ Parameter } & Required Values \\
\hline Surface Outgassing Rates & & $\begin{array}{l}10^{-10} \mathrm{~T}-\mathrm{L} / \mathrm{sec} / \mathrm{cm}^{2} \\
\text { @ } 100 \mathrm{hr} \text { post-cond } \\
2.5 \times 10^{-9} \mathrm{~T}-\mathrm{L} / \mathrm{sec} / \mathrm{cm}^{2} \\
\text { @ } 100 \mathrm{hr} \text { post-cond }\end{array}$ \\
\hline $\begin{array}{l}\text { Drift tube average pressure } \\
\text { Post-rf conditioned } \\
\text { Normal operation: All pumps } \\
\text { functioning }\end{array}$ & $\begin{array}{l}\text { Design } \\
\text { Required }\end{array}$ & $\begin{array}{l}9.2 \times 10^{-8} \text { Torr } \\
\text { for mixed gas } \\
<1.84 \times 10^{-7} \text { Torr } \\
\text { for mixed gas }\end{array}$ \\
\hline $\begin{array}{l}\text { Drift tube average pressure } \\
\text { Post-rf conditioned } \\
\text { Failure Mode: one ion pump fails }\end{array}$ & $\begin{array}{l}\text { Design } \\
\text { Required }\end{array}$ & $\begin{array}{l}1.84 \times 10^{-7} \text { Torr } \\
\text { for mixed gas } \\
<1.84 \times 10^{-7} \text { Torr } \\
\text { for mixed gas }\end{array}$ \\
\hline
\end{tabular}

Table 2: SNS/CCL Vacuum System Requirements

\begin{tabular}{|c|c|c|}
\hline Parameter & & Required Values \\
\hline Surface Outgassing Rates & & $\begin{array}{l}10^{-10} \mathrm{~T}-\mathrm{L} / \mathrm{sec} / \mathrm{cm}^{2} \\
@ 100 \mathrm{hr} \text { post-cond } \\
2.5 \times 10^{-9} \mathrm{~T}-\mathrm{L} / \mathrm{sec} / \mathrm{cm}^{2} \\
@ 100 \mathrm{hr} \text { post-cond }\end{array}$ \\
\hline $\begin{array}{l}\text { Beamline average pressure } \\
\text { Post-rf conditioned } \\
\text { Normal operation: All pumps } \\
\text { functioning }\end{array}$ & $\begin{array}{l}\text { Design } \\
\text { Required }\end{array}$ & $\begin{array}{l}8.9 \times 10^{-8} \text { Torr } \\
\text { for mixed gas } \\
<4.4 \times 10^{-8} \text { Torr } \\
\text { for mixed gas }\end{array}$ \\
\hline $\begin{array}{l}\text { Beamline average pressure } \\
\text { Post-rf conditioned } \\
\text { Failure Mode: one ion pump fails }\end{array}$ & $\begin{array}{l}\text { Design } \\
\text { Required }\end{array}$ & $\begin{array}{l}8.9 \times 10^{-8} \text { Torr } \\
\text { for mixed gas } \\
<8.9 \times 10^{-8} \text { Torr } \\
\text { for mixed gas }\end{array}$ \\
\hline
\end{tabular}

\section{DESIGN AND ANALYSIS}

\subsection{Numerical Model- DTL}

The numerical model of the vacuum system models the gas load balance between the DTL tank, a representative drift tube section, and the vacuum pumps. The sketch in Fig. 2 shows the layout of the volumes to be evacuated and the division into 7 subvolumes and interconnecting conductances. Four subvolumes represent each tank quadrant and three represent two drift tubes and the gap in between them. These drift tubes are attached to the 4th tank quadrant. The geometry of the representative drift tubes uses the longest drift tube in the tank. It also illustrates the placement of quadrupole magnets, seals and O-rings. Pressure history is studied by solving the coupled gas load equations between all the sub-volumes, with the pressure dependence of the ion pump speed taken into account. The pumpdown curve for the optimized design is shown in Fig. 3.

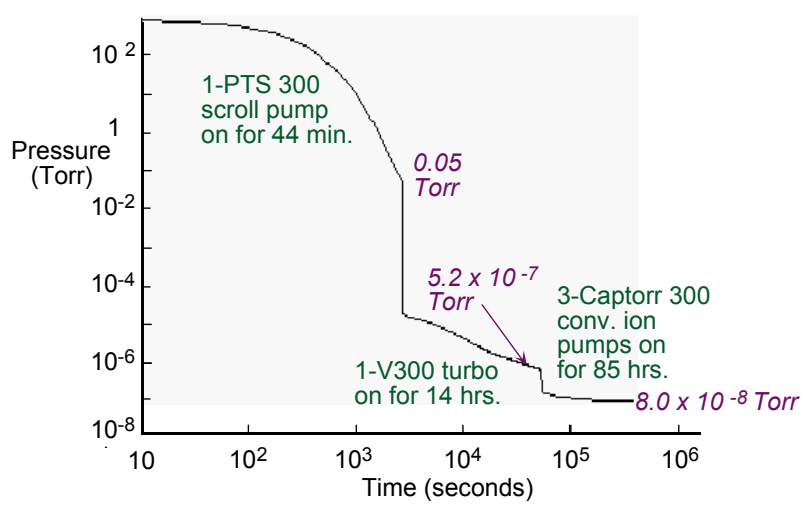

Figure 3: Pumpdown Curve for the DTL system 


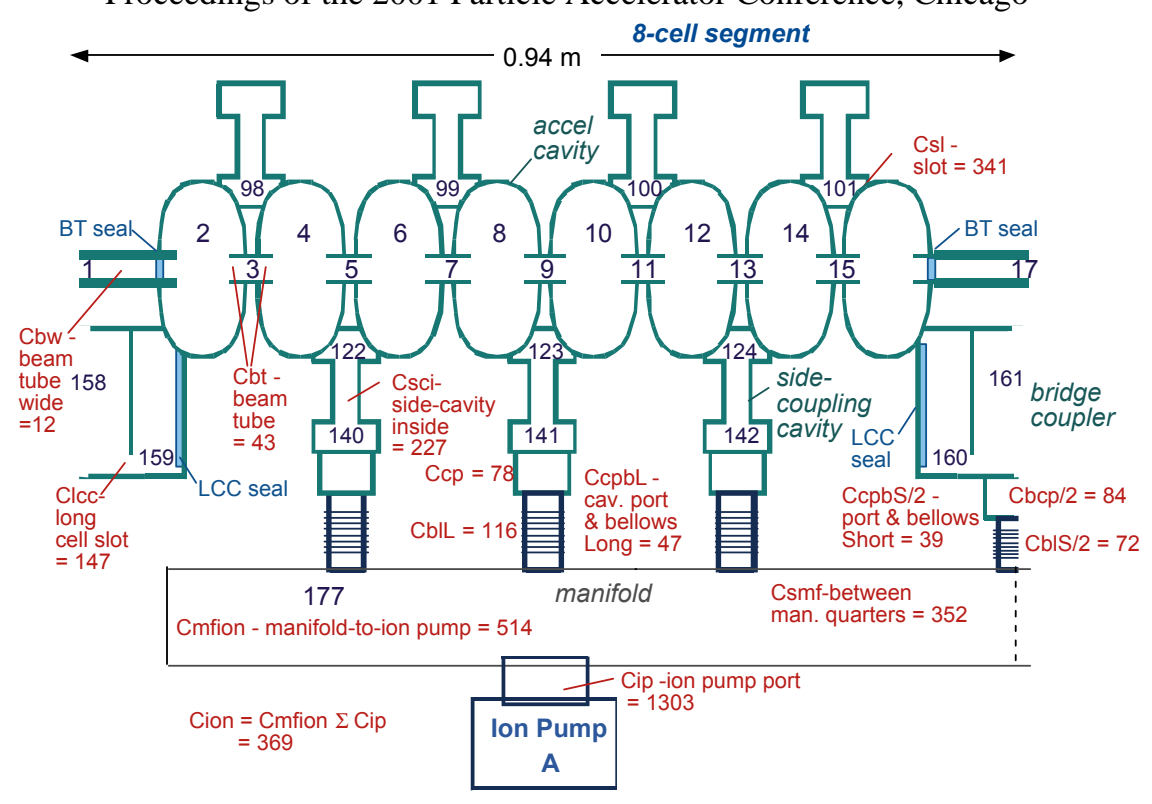

Fig. 4: Layout of $1^{\text {st }}$ of 6 segments of sub-volumes and conductances in the model of CCL

\subsection{Numerical Model- CCL}

The model of the CCL vacuum system is prepared to analyze the gas load balance between half of a module. The length of a half module is approximately 5.6 meters, which is the longest recommended for manufacturing and handling the vacuum manifold. Fig. 4 shows the model representation of the 6 segments (half of a module), bridge couplers, beam tubes, vacuum manifold, bellows, pumps, and the interconnecting conductances. In all, the model is divided into $182 \mathrm{sub}$ volumes. Analytical results can be summarized in Fig. 5, where the optimization of the number of pumps is illustrated, and in Fig. 6 where the pumpdown curve of the Module 1 is shown.

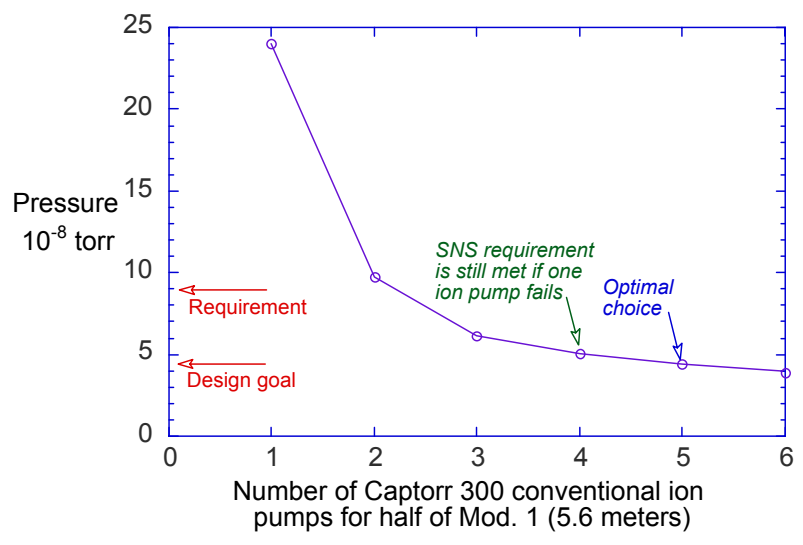

Fig. 5: Average Beamline pressure versus number of Captorr 300 ion pumps for half of a CCL module

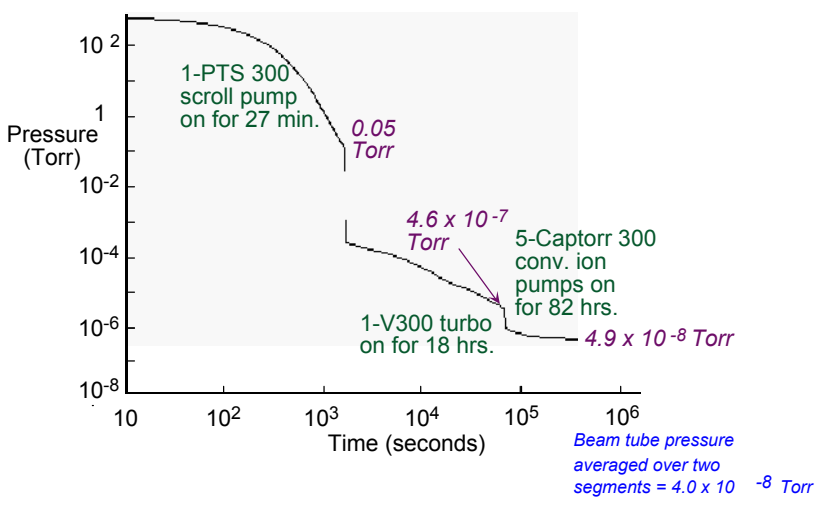

Fig. 6: Pumpdown Curve for CCL Module-1

\section{CONCLUSION}

The design of SNS DTL and CCL vacuum systems are presented. The modeling results presented in this paper validated the design of the vacuum system. It is also demonstrated that the vacuum system is capable of providing comfortable vacuum levels for SNS linac operation.

\section{REFERENCES}

[1] J. Benardin, "Spallation Neutron Source Drift Tube Linac and Coupled Cavity Linac Vacuum System Description Document," SNS-104020400-TR0002R01, Spallation Neutron Source Division,

Los Alamos National Laboratory, 2000. 